\title{
Uma improvável dor de cotovelo: relato de um caso de tuberculose dos tecidos moles
}

\author{
Catarina Miranda, ${ }^{1}$ Alexandra Pinto, ${ }^{2}$ Célia Madalena, ${ }^{3}$ Luís Nora e Sousa, ${ }^{4}$ Teresa Febra ${ }^{5}$
}

\section{RESUMO}

Introdução: Em Portugal, a percentagem de casos de tuberculose que tem localização extrapulmonar estima-se em $29 \%$. As localizações mais frequentes são a ganglionar, pleural, osteoarticular e meníngea. A prevalência de tuberculose como problema de saúde pública e escassez de casos descritos de tuberculose de tecidos moles ilustram a pertinência deste relato.

Descrição do caso: Jovem do sexo feminino, 17 anos de idade, saudável até fevereiro de 2013, altura em que iniciou quadro de dor à mobilização ativa do cotovelo direito, sem história traumática, tendo sido medicada com anti-inflamatório. Por persistência das queixas álgicas e surgimento de sinais inflamatórios locais, realizou estudo ecográfico, solicitado pelo médico de família, que revelou uma área de edema e celulite dos tecidos moles periarticulares. Em maio, após insucesso terapêutico com dois ciclos de antibioterapia oral, recorreu ao serviço de urgência do Centro Hospitalar Póvoa de Varzim/Vila do Conde. Foi posteriormente internada no serviço de pediatria. Apresentava tumefação na face externa do cotovelo, com sinais de flutuação, dolorosa à palpação, sem compromisso da mobilidade articular. Foi realizada punção aspirativa local, cujo exame cultural foi positivo para Mycobacterium tuberculosis. A prova tuberculínica mostrou enduração de $13 \mathrm{~mm}$. A ressonância magnética nuclear do cotovelo foi sugestiva de lesão infeciosa de etiologia tuberculosa. A doente foi orientada para o Centro de Diagnóstico Pneumológico com o diagnóstico de tuberculose de tecidos moles, iniciou terapêutica tuberculostática tripla, apresentando evidente melhoria clínica após um mês de tratamento.

Discussão: Apesar da sua raridade, a tuberculose de tecidos moles deve ser uma hipótese de diagnóstico a considerar em lesões localizadas, persistentes e resistentes a terapêutica antibiótica, sobretudo em áreas geográficas onde a prevalência de tuberculose não seja desprezível.

Palavras-chave: Tuberculose; Infeção de Tecidos Moles; Cotovelo.

\section{INTRODUÇÃO}

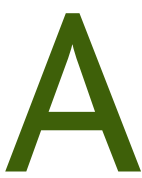
pesar do decréscimo constante da taxa de incidência de tuberculose nos últimos 12 anos, ${ }^{1}$ Portugal continua a assumir-se como um país de incidência intermédia (o único da Europa Ocidental). ${ }^{1}$ Desde 2004 tem-se assistido a uma atenuação das assimetrias na distribuição geográfica dos casos de tuberculose a nível nacional, desaparecendo áreas de alta incidência (50 ou mais casos por 100 mil habitantes). ${ }^{1}$ No entanto, em 2012, os distritos deViana do Castelo, Porto, Lisboa e Setúbal, mantinham ainda incidência intermédia (mais de 20 e menos de 50 casos por 100 mil habitantes). ${ }^{1}$

${ }^{1}$ Médica Interna de Medicina Geral e Familiar. Unidade de Saúde Familiar do Mar, ACeS Grande Porto IV - Póvoa de Varzim/Vila do Conde

${ }^{2}$ Médica Interna de Pediatria, Centro Hospitalar de Lisboa Norte - Hospital de Santa Maria

${ }^{3}$ Médica Assistente de Pediatria, Centro Hospitalar Póvoa de Varzim/Vila do Conde ${ }^{4}$ Médico Assistente de Ortopedia, Centro Hospitalar Póvoa de Varzim/Vila do Conde ${ }^{5}$ Médica Assistente Graduada de Medicina Geral e Familiar, Centro de Diagnóstico Pneumológico, ACeS Grande Porto IV - Póvoa de Varzim/Vila do Conde
Assim, a infeção por Mycobacterium tuberculosis continua a ser um grave problema de saúde pública em Portugal.

A percentagem de casos de tuberculose que tem localização extrapulmonar aumentou de 16,4\% em 2002 para $22,4 \%$ em 2011, na Europa, sendo mais frequente em indivíduos positivos para o vírus da imunodeficiência humana (VIH). ${ }^{2}$ Em Portugal, 27,5\% dos casos de tuberculose notificados em 2012 foram de etiologia exclusivamente extrapulmonar $(31 \%$ dos quais corresponderam a atingimento pleural e $26 \%$ a atingimento linfático extratorácico). ${ }^{1} \mathrm{Já}$ em 2013, no nosso país, a percentagem de casos de tuberculose que tinha localização extrapulmonar foi estimada em 29\%. ${ }^{3}$ As localizações extrapulmonares mais frequentes são a ganglionar, pleural, osteoarticular e meníngea.

São escassos os casos de tuberculose de tecidos moles descritos na literatura. ${ }^{4-5} \mathrm{~A}$ pertinência deste caso clínico reside na ilustração de uma apresentação clínica rara (logo, com particular dificuldade diagnóstica) de uma doença frequente entre nós. 


\section{DESCRIÇÃO DO CASO}

Jovem, sexo feminino, 17 anos de idade, caucasiana, estudante do $11 .^{\circ}$ ano de um curso profissional (estética), natural e residente na Póvoa de Varzim. Pertence a uma família nuclear e é a segunda de uma fratria de dois irmãos. Sem antecedentes pessoais (patológicos ou cirúrgicos) relevantes, sem alergias conhecidas, sem hábitos tabágicos, alcoólicos ou consumo de drogas de abuso. O Programa Nacional deVacinação encontrava-se atualizado. Medicada com contracetivo oral combinado há um ano por irregularidade menstrual e dismenorreia.

Em fevereiro de 2013 iniciou dor moderada à mobilização ativa do cotovelo direito sem história de traumatismo, picada de inseto ou inoculação vacinal, sem deformidade ou sinais inflamatórios locais. A doente recorreu ao serviço de urgência do Centro Hospitalar Póvoa de Varzim/Vila do Conde após duas semanas de evolução do quadro e, perante a normalidade do estudo imagiológico radiográfico, teve alta medicada com diclofenac tópico.

Dois meses depois, a 10 de abril, recorreu à consulta com o seu médico de família por persistência das queixas álgicas. A dor era bem localizada, de intensidade moderada e sem ritmo preferencial ao longo do dia. A doente negava fatores desencadeantes ou agravantes, bem como outros sintomas, nomeadamente constitucionais (febre, fadiga, anorexia ou emagrecimento), mucocutâneos, oculares, pulmonares ou gastrointestinais. Ao exame físico apresentava bom estado geral, apirexia e edema da face póstero-lateral do cotovelo direito numa área de cerca de $3 \mathrm{~cm}$, sem outros sinais inflamatórios e sem alterações cutâneas. A mobilização ativa e passiva da articulação era moderadamente dolorosa, mas não condicionava limitação funcional. Foi solicitada ecografia de partes moles e prescrito anti-inflamatório oral (aceclofenac 100mg de 12 em 12 horas durante sete dias), sem melhoria significativa.

O estudo ecográfico revelou "edema e celulite focal em posição póstero-externa” e uma "área lesionada com $30 \mathrm{~mm}$ no eixo sagital e $7 \mathrm{~mm}$ no eixo ântero-posterior", sem afeção dos tendões infrajacentes, sem bursite ou sinais de rotura. A 30 de abril, e perante este resultado, foi medicada com antibiótico (flucloxaciclina 500mg de $8 \mathrm{em}$ 8 horas durante oito dias) e foi solicitada radiografia do cotovelo, que se revelou normal.

Perante o resultado radiográfico e por manutenção do quadro clínico, a 10 de maio, foi alterada antibioterapia para a associação amoxicilina e ácido clavulânico 875 + 125mg de 12 em 12 horas durante oito dias. Foi recomendado à doente a recorrência à consulta em caso de insucesso terapêutico.
A 16 de maio, por ausência de melhoria, a doente recorreu por sua iniciativa ao serviço de urgência do hospital da área de residência, onde foi observada por ortopedia. Mantinha edema e agora flutuação da região pósterolateral do cotovelo direito, sem adenomegalias axilares palpáveis (Figura 1A). A palpação da lesão permanecia dolorosa, embora sem compromisso da amplitude articular. Foi efetuada punção aspirativa da tumefação, com drenagem de conteúdo hemato-purulento em quantidade significativa, enviado para exame microbiológico direto e cultural. Teve alta com indicação para regressar ao serviço de urgência quatro dias depois para reavaliação clínica.

A 20 de maio, por persistência do quadro clínico, foi decidido internamento no serviço de pediatria para repetição de punção aspirativa e instituição de antibioterapia endovenosa (amoxicilina + ácido clavulânico 2000 + 200mg de 8 em 8 horas), além de anti-inflamatório oral (ibuprofeno $600 \mathrm{mg}$ de $12 \mathrm{em} 12$ horas). A doente mantinha edema com discreta melhoria dos sinais inflamatórios e a amplitude articular continuava preservada. O exame bacteriológico em aerobiose e anaerobiose, direto e cultural, foi negativo, bem como a pesquisa de bacilos álcool-ácido resistentes (coloração Ziehl-Neelsen). Teve alta ao fim de quatro dias, melhorada, orientada para a consulta externa de ortopedia.

Na consulta de ortopedia, a 30 de maio, o quadro clínico persistia, embora negasse agravamento das queixas ou aumento da área lesada. Não apresentava sintomas de novo, nomeadamente febre, anorexia, perda ponderal, suores noturnos ou fadiga, bem como tosse ou infeção respiratória recente. O exame micobacteriológico cultural da primeira colheita revelou-se positivo para Mycobacterium tuberculosis. Desconhecia conviventes ou contactos próximos doentes e negava viagens recentes. Foi solicitada colaboração imediata de pediatria para continuação do estudo e orientação terapêutica, tendo sido observada em consulta urgente no mesmo dia.

A 6 de junho foram conhecidos os resultados da investigação adicional. Do estudo efetuado destaca-se: velocidade de sedimentação de $41 \mathrm{~mm} /$ h e proteína C reativa de $1,37 \mathrm{mg} / \mathrm{dL}$; serologia VIH negativa; radiografia do tórax com discreto reforço hilar à esquerda; prova tuberculínica com enduração de 13 mm e com flictena; pesquisa de bacilo de Koch no suco gástrico negativa nas três amostras; e ressonância magnética nuclear do cotovelo com "volumosa coleção líquida centrada na gordura subcutânea da vertente posterior externa do cotovelo (...) compatível com lesão infeciosa de etiologia tuberculosa (...)" (Figura 2). Perante estes resultados, quatro meses após o início do qua- 


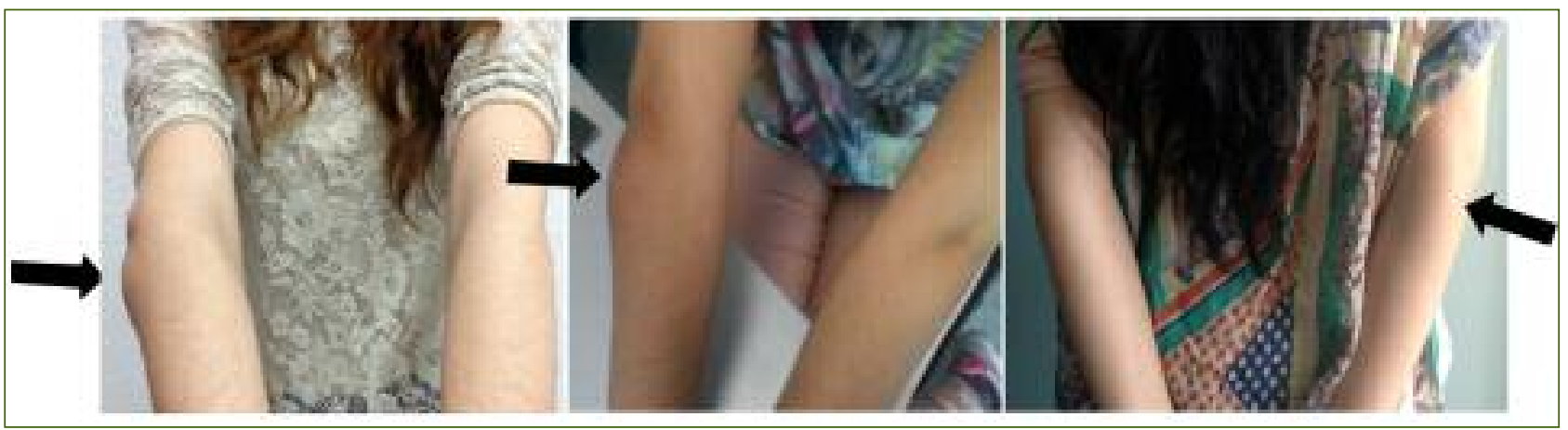

Figura 1. (A) - Edema da face póstero-lateral do cotovelo direito (serviço de urgência, maio de 2013); (B) - Melhoria após um mês de terapêutica tuberculostática (consulta de pediatria, julho de 2013); (C) - Ausência de lesão (Centro de Diagnóstico Pneumológico, outubro de 2013, vista de costas).

dro, foi efetuado o diagnóstico de tuberculose de tecidos moles do cotovelo direito (extra-articular), caso confirmado de tuberculose-doença.

A doente foi encaminhada para o Centro de Diagnóstico Pneumológico para instituição e monitorização da terapêutica. Foi instituída terapêutica tuberculostática tripla com rifampicina $120 \mathrm{mg}$ + isoniazida $50 \mathrm{mg}$ + pirazinamida 300mg (cinco comprimidos/dia) associada a piridoxina 300mg um comprimido/dia e feito acompanhamento com consultas com periodicidade mensal.

Decorrido um mês do início do tratamento, em consulta de pediatria, apresentava melhoria franca das queixas, bem como diminuição do edema do cotovelo (Figura 1B). Aos dois meses surgiu assintomática, sem qualquer alteração ao exame objetivo, tendo-se suspendido pirazinamida, mantendo rifampicina $300 \mathrm{mg}+$ isoniazida $150 \mathrm{mg}$, dois comprimidos/dia e piridoxina 300mg um comprimido/dia. No percurso terapêutico, a doente apresentou como efeitos laterais discreta trombocitopenia, fotossensibilidade e irregularidades menstruais, transitórias. Após quatro meses de tratamento, em outubro (Figura 1C), realizou ecografia do cotovelo que já não evidenciou qualquer alteração.

A doente cumpriu seis meses de terapêutica tuberculostática, tendo tido alta da consulta do Centro de Diagnóstico Pneumológico em fevereiro de 2014, orientada para o seu médico de família, mantendo-se assintomática até à data.

\section{COMENTÁRIO}

A tuberculose extrapulmonar constitui um desafio diagnóstico. A maioria das formas extrapulmonares ocorre em órgãos sem condições ótimas de crescimento bacilar, sendo quase sempre de instalação insidiosa e evolução lenta. ${ }^{6}$ Uma vez que as lesões são habitualmente paucibacilares, a con- firmação diagnóstica é possível em apenas $1 / 4$ dos casos. ${ }^{6}$

Das formas de tuberculose extrapulmonar descritas na literatura, as que poderiam suscitar diagnóstico diferencial com o presente caso seriam a tuberculose osteoarticular (cerca de $35 \%$ de todos os casos de tuberculose extrapulmonar $)^{7}$ e a cutânea. ${ }^{6}$ Na sua forma articular, a tuberculose manifesta-se geralmente como uma monartrite lentamente progressiva, mais frequentemente na articulação coxofemoral ou joelho, em que a sintomatologia sistémica é incomum, mas existe limitação da amplitude do movimento e achados imagiológicos (osteopenia justa-articular, diminuição da interlinha articular e erosões subcondrais). ${ }^{7} \mathrm{~A}$ tu-

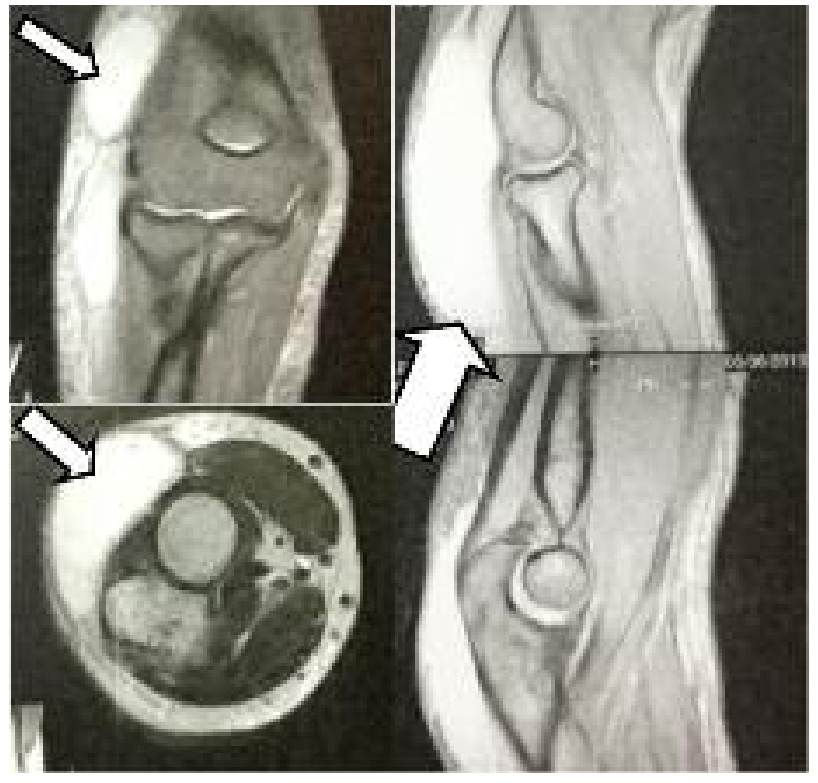

Figura 2. Coleção líquida na gordura subcutânea do cotovelo direito compatível com infeção de etiologia tuberculosa (imagem de ressonância magnética nuclear, junho de 2013). 
berculose cutânea, por seu lado, é, na maioria dos casos, uma manifestação secundária da doença, podendo manifestar-se por úlceras, vegetações, nódulos e hiperqueratose, fístulas ou escrofuloderma. Esta última representa a fistulização cutânea espontânea a partir de gânglios afetados, sendo a forma mais comum de tuberculose cutânea. ${ }^{6}$

A tuberculose de tecidos moles é uma entidade clínica rara. ${ }^{8}$ Encontram-se descritas séries de $\operatorname{casos}^{4-5}$ que relatam antecedentes de doença vascular do colagénio, imunossupressão (farmacológica ou por infeção VIH) ou traumatismo prévio, bem como história ou radiografia torácica compatível com tuberculose. Este caso, em particular, refere-se a uma jovem previamente saudável, contrariando a epidemiologia mais frequente relatada na literatura.

A apresentação clínica deste caso, localizada e frustre, dirigiu a investigação e o tratamento inicial às suas causas mais comuns. Posteriormente, o facto de a lesão persistir há mais de três meses, bem como as características epidemiológicas da tuberculose na área de residência da doente, levaram a que a tuberculose fosse incluída no diagnóstico diferencial do estudo patológico, ainda que não se apurassem fatores de risco pessoais para patologia infeciosa micobacteriana.

Apesar da sua raridade, a tuberculose de tecidos moles deve ser uma hipótese de diagnóstico a considerar em lesões localizadas, persistentes e resistentes à terapêutica antibiótica, sobretudo em áreas geográficas onde a prevalência de tuberculose não é desprezível.

\section{REFERÊNCIAS BIBLIOGRÁFICAS}

1. Duarte R, Diniz A. Programa nacional de luta contra a tuberculose: ponto da situação epidemiológica e de desempenho (dados provisórios). Lisboa: Direção-Geral da Saúde; 2013.

2. European Centre for Disease Prevention and Control. TB situation in 2011: findings from the ECDC and WHO/EURO joint TB surveillance report [lnternet]. In World Tuberculosis Day 2013, Stockholm (Sweden), 24 March 2013.Available from:http://pt.slideshare.net/StopTbltalia/tuberculosis-surveillancemonitoringineu2013slides 1

3. Hollo V, Dadu A, editors. Tuberculosis surveillance and monitoring in Europe 2015. Stockholm: European Centre for Disease Prevention and Control; 2015. ISBN 9789291936243

4. Puttick MP, Stein HB, Chan RM, Elwood RK, How AR, Reid GD. Soft tissue tuberculosis: a series of 11 cases. J Rheumatol. 1995;22(7):1321-5.

5. Hugosson C, Nyman RS, Brismar J, Larsson SG, Lindahl S, Lundstedt C. Imaging of tuberculosis. V. Peripheral osteoarticular and soft tissue tuberculosis. Acta Radiol. 1996;37(4):512-6.

6. Lopes AJ, Capone D, Mogami R, Tessarollo B, Cunha DL, Capone RB. Tuberculose extrapulmonar: aspectos clínicos e de imagem [Extrapulmonary tuberculosis: clinics and image aspects]. Pulmão RJ. 2006;15(4):253-61. Portuguese

7. Golden MP, Vikram HR. Extrapulmonary tuberculosis: an overview. Am Fam Physician. 2005;72(9):1761-8.

8. De Backer Al, Vanhoenacker FM, Sanghvi DA. Imaging features of extraaxial musculoskeletal tuberculosis. Indian J Radiol Imaging. 2009;19(3):176-86.

\section{CONFLITO DE INTERESSE}

Os autores declaram não possuir quaisquer conflitos de interesse.

\author{
ENDEREÇO PARA CORRESPONDÊNCIA \\ Ana Catarina Dias Miranda \\ R. Vasconcelos e Castro, 122, Apart. 56, 4760-169 Vila Nova de Famalicão \\ E-mail: catarinadm@gmail.com
}

Recebido em 07-04-2015

Aceite para publicação em 05-12-2015

\section{ABSTRACT}

\section{AN UNCOMMON CAUSE OF ELBOW PAIN: A CASE REPORT OF TUBERCULOSIS OF SOFT TISSUES}

Introduction: Extrapulmonary tuberculosis is found in $29 \%$ of cases in Portugal. The most common sites are lymph nodes, pleura, bone, joints, and meninges. The high prevalence of tuberculosis in Portugal and the scarcity of reported cases of tuberculosis of soft tissues highlight the importance of this case report.

Case presentation: A 17 year-old female was healthy until February of 2013 when she began to complain of pain on movement of the right elbow. There was no history of trauma. She was treated with anti-inflammatory medication. Because of persistent pain and the appearance of signs of local inflammation, an ultrasound examination of the elbow was requested by the family doctor. This revealed an area of edema and cellulitis in the peri-articular soft tissues. After failure of treatment with two courses of oral antibiotics, she went to the emergency department of Centro Hospitalar Póvoa do Varzim/Vila do Conde where she was admitted to the pediatric department. She presented with swelling of the lateral aspect of the elbow with fluctuation and tenderness to palpation, but without restriction of mobility of the joint. A local aspiration was performed and culture of the fluid was positive for Mycobacterium tuberculosis. The tuberculin skin test showed an induration of $13 \mathrm{~mm}$. Nuclear magnetic resonance imaging of the elbow was suggestive of an infectious lesion of tuberculosis etiology. The patient was referred to the Centre for Pulmonary Diagnosis with a diagnosis of tuberculosis of soft tissues. She began triple tuberculostatic therapy, with clinical improvement after one month of treatment.

Discussion: Although it is rare, tuberculosis of soft tissues should be considered in localized, persistent lesions that are resistant to antibiotic treatment, especially in geographical areas with a high prevalence of tuberculosis.

Keywords: Tuberculosis; Soft Tissue Infection; Elbow. 